Vol. 10(25), pp. 526-532, 8 July, 2016

DOI: 10.5897/AJPP2015.4490

Article Number: 63E989959487

ISSN 1996-0816

Copyright (C) 2016

Author(s) retain the copyright of this article

http://www.academicjournals.org/AJPP

\title{
Cubebin and semisynthetic dibenzyl butyrolactone derivatives: Biological activities
}

\author{
Pereira C.C. S. S. ${ }^{1 \star}$, Perazzo, F. F. ${ }^{2}$, Souza G. H. B. ${ }^{3}$, Fonseca, F. L. A. ${ }^{2,4}$ and Rosa P. C. $P^{1}$ \\ ${ }^{1}$ Faculty of Pharmaceutical Sciences, University of Campinas, Campinas, São Paulo, Brazil. \\ ${ }^{2}$ Departamento de Ciências Exatas e da Terra, Diadema, University Federal of São Paulo, São Paulo, Brazil. \\ ${ }^{3}$ Department of Pharmacy, University Federal of Ouro Preto, School of Pharmacy, Ouro Preto, Minas Gerais, Brazil. \\ ${ }^{4}$ ABC Foundation School of Medicine, Santo André, São Paulo, Brazil.
}

Received 18 November, 2015; Accepted 17, June, 2016

\begin{abstract}
Lignans are a group of secondary metabolites with a wide variety of chemical structures, formed by coupling two phenylpropanoid units. Currently, there is great interest in lignan due to the wide range of biological activities this class of compounds has demonstrated. This review describes the biological activities of cubebin and semi-synthetic derivatives, focusing primarily on Piper cubeba and Zantoxyllum naranjillo. The main biological activities reported were: Anti-inflammatory, antitumor, action in erectile dysfunction, trypanocidal, anti-Leishmania and antimicrobial. In this way, it is possible to conclude that cubebin and its derivatives have shown high capacity to become new bioactive molecules obtained by semi-sinthesys, useful to develop medicines for several pathologies, presenting efficacy, toxicology and quality for human use.
\end{abstract}

Key words: lignans; cubebin, semisynthetic derivatives; biological activities, Piper cubeba, Piperaceae, Zantoxyllum naranjillo, Rutaceae.

\section{INTRODUCTION}

In the 1940s, Haworth introduced the term lignan to refer to a class of chemical plant compounds originating from the biosynthetic pathway of shikimic acid, which are formed by oxidative coupling of cinnamyl alcohols among themselves or cinnamic acids (Barbosa Filho, 2004). The way these phenylpropanoid units connect (C6C3) determines their classification. Lignans are connected by position 8 and 8 ' of the aliphatic chain (Simões et al., 1999).

Lignans are an important group of secondary metabolites found in many plant species. They are mostly found in nature in its free form, widely distributed in plants. It has been found in species from more than 70 families, isolated from roots, rhizomes, stems, leaves, seeds and fruits (Saleem et al., 2005).

Lignans are formed in response to mechanical injury or invasion of fungi or bacteria. They have several beneficial properties including analgesic, anti-inflammatory (Bastos et al., 2001), antitumor (Yan et al., 2008), trypanocidal (Bastos et al., 1999; de Souza et al., 2005) and anti-

${ }^{*}$ Corresponding author. E-mail: carlascarpa@yahoo.com.br.

Author(s) agree that this article remain permanently open access under the terms of the Creative Commons Attribution License 4.0 International License 
Leishmania activity (Bodiwala et al., 2007).

Cubebin is a lignan dibenzyl butyrolactone found in a wide variety of plant families around the world (Rao, 1978). For example Aristolochiaceae (De Pascoli et al., 2006), Rutaceae (Bastos et al., 2001), Myristicaceae (Blumenthal et al., 1997) and Piperaceae (Saraiva et al., 2007) have been investigated for different activities of cubebin, especially $P$. cubeba and $Z$. naranjillo.

Zantoxyllum naranjillo Griseb (Rutaceae) has been used to treat inflammation (Reitz, 1960). In this species cubebin was isolated from a hexane leaves. Piper cubeba Linn (Piperaceae) is a popular spice used in Europe and countries such as Saudi Arabia, India, Indonesia and Morocco (Junqueira et al., 2007). Pepper has been used since the Middle Ages, both as a spice and in traditional medicine to treat various diseases. The genus Piper has more than 1000 species that grow as herbs, shrubs or trees (Junqueira et al., 2007). Cubebin has been isolated from the $P$. cubeba dry seeds.

Non clinical studies such as Rodrigues (2002) indicated that cubebin has no toxic effects when administered orally. Therefore, it is important to evaluate this compound and its derivatives for therapeutic purposes.

In most articles reviewed the cubebin was isolated from $P$. cubeba seeds. The reason for the preference should possibly have been because the isolation from the leaves of $Z$. naranjillo could put the species on risk of extinction.

Research on natural products contributes effectively to the discovery of new drugs. It can occur by introducing new chemical structures and/or mechanisms of action.

Principles derived from natural products assets are extremely important in expanding the therapeutic arsenal as well as improving patients' quality of life, aiming at the development of effective drugs with high clinical potency and reduced side effects.

Cubebin is a very active substance in several pathological conditions as described previously. It is well known that some minor changes in the structure of the molecule can greatly improve their activity by interfering in its mechanism of action or even important pharmacokinetic parameters such as partition coefficient and dissociation coefficient.

The purpose of this article is to review the semisynthetic derivatives that have been produced from cubebin and how they act in relation to the tested activity, using pharmaceutical chemistry to further improve the activity of natural compounds with insertion various substituent's on the molecule.

\section{MATERIALS AND METHODS}

Pharmacological activities of cubebin and its derivatives were studied by using the PUBMED search engine, comprising citations for biomedical literature of MEDLINE database, science journals and eBooks. LILACS was another database used, coordinated by BIREME/PAHO/WHO, The Latin American and Caribbean Center on Health Sciences Information, belonging to the Pan American Health Organization. Data were consulted in June 2016, and the following key words were used: Cubebin, piper cubeba, cubebin/piper cubeba, and cubebin/zantoxyllum naranjillo.

\section{RESULTS AND DISCUSSION}

\section{Inflammatory and analgesic activities}

Inflammation is an immune system coordinated response to noxious stimuli that appear during infection or after a tissue injury. The inflammatory response is the result of several chemical mediators' activity released by immune cells and in loco activated biochemical response (Stutz et al., 2009).

Prostaglandins are potent inflammation mediators, and non-steroidal anti-inflammatory drugs act by inhibiting its production. Cyclooxygenase is the pharmacological target of these drugs. It is involved in the first step of arachidonic acid metabolism. Two cyclooxygenase isoforms are known, COX-1 and COX-2. The first is a constitutive isoform found in blood vessels, stomach and kidney, while COX-2 is preferred induced by cytokines in inflammatory context and inflammation mediators. It is desirable that the medicine preferentially inhibit, selectively, COX-2 in order to avoid ulcerogenic side effects typical of these drugs. When used as analgesics, these drugs are generally only effective for mild to moderate pain (Hardman et al., 1996).

Bastos et al. (2001) used in a study the paw edema model induced by carrageenan. Cubebin was isolated from the leaves of Zanthoxyllum naranjillo. In that study cubebin was tested and compared to indomethacin, which is a non-steroidal anti-inflammatory, used as a positive control. The researchers observed that carrageenan produced a significant edema in paws of rats, which was more intense in animals treated with $5 \%$ Tween (negative control). Cubebin $(10 \mathrm{mg} / \mathrm{kg})$ taken 30 minutes before carrageenan injection, inhibited in a very similar way to the same oral dose of indomethacin. In this study, the research group also used other inflammation models as edema induced by dextran, edema induced by histamine, edema induced by serotonin and edema induced by prostaglandin PGE2. Of these, cubebin was able to partially inhibit the edema induced by serotonin and significantly the edema induced by prostaglandin.

Analgesic and anti-inflammatory effects of cubebin and its derivative benzylated, (-) o-benzyl cubebin, were investigated using different models of animal testing. Cubebin was isolated from $P$. cubeba dry seeds.

This study was conducted by Coimbra et al. (2004). The (-) o-benzyl cubebin showed low anti-inflammatory activity and high analgesic activity, producing doseresponse correlation in doses of 10,20 and $40 \mathrm{mg} / \mathrm{Kg}$. In the hot plate test and cell migration, neither cubebin nor its derivative showed activity. In this way, according to the research group, adding benzyl group contributed only for analgesic activity.

Souza et al. (2004) conducted a study in order to obtain 
(-)-O-acetyl, (-)-O-methyl, (-)-O-dimethylamylimine cubebin from cubebin (isolated from dry seeds of $P$. cubeba $L$.) and test their analgesic and anti-inflammatory activities. These compounds were respectively obtained by acetylation, methylation and amination of the cubebin hydroxyl group. According to the results, the researchers concluded that acetylation and amination of cubebin increased analgesic and anti-inflammatory activities. Regarding the hot plate and the cell migration test of rats none of the four compounds showed activity.

Silva et al. (2005) tested cubebin and its derivatives: hinokinin, 6.6-dinitro hinokinin and 6.6-diamino hinokinin isolated from $P$. cubeba dry seeds in different animal models.

In the paw edema model induced by carrageenan, responses were compared to indomethacin. In this study, carrageenan in rat paws induced a high edematogenic response and treatment of the animals with cubebin and its derivatives variously inhibited, but also significant, edema formation. According to Silva et al. (2005) the introduction of groups $-\mathrm{NH}_{2}, 6.6$-diamino hinokinin may be beneficial to the activity ( $82 \%$ inhibition) and different substitutions may affect selectivity by COX2. In the writhing test induced by acetic acid in rats, the compounds hinokinin and 6.6-diamino hinokinin showed inhibition levels of 97 and $92 \%$, respectively. Silva et al. (2005) found that polar groups introduction on aromatic rings is advantageous for analgesic and antiinflammatory activities.

\section{Antitumor activity}

Carcinogenesis is a complex process that occurs from the interaction between a carcinogenic agent (or oncogenic) and genes, changing cell characteristics, losing control of cell division and culminating in a uncontrolled growth of neoplastic cells (Mainenti and Rosa, 2008; Vainio et al., 1992).

The oncogenic agents do not necessarily have exogenous origin. The free radicals derived from the very metabolic processes of an aerobic organism generate a cellular oxidative stress. This contributes to aging development, transformation and cell death, which relate to many disease processes, including cancer and other chronic diseases (Vasconcelos et al., 2007). Phenolic substances are known to be holders of pronounced antioxidant properties, acting as free radical scavengers and as metal chelator (Pessuto et al., 2009) for the formation of phenoxyl radical.

In the Aboul-Eneim et al. (2011) study, the antioxidant activity of 16 compounds isolated from $P$. cubeba, among them cubebin, was measured by the ability to eliminate free radicals: Hydroxyl radical $\left(\mathrm{OH}^{-}\right)$, superoxide anion radical $\left(\mathrm{O}_{2}^{-{ }^{-}}\right)$, and 2.2-diphenyl-1-picrylhydrazyl radical (DPPH) in different systems. The results showed that most of the tested compounds acted as free radical scavenger under in vitro conditions and can act as antioxidant agents for anti-free radical mechanism.

Rezende et al. (2011) evaluated the genotoxic potential and influence on chromosomal damage induced by doxorubicin in V79 cells and by urethane in somatic cells of Drosophila melanogaster. It was concluded that cubebin has antioxidant ability, acting as free radical scavenger at low concentrations, a pro-oxidant at higher concentrations when it interacts with the enzyme system which catalyzes metabolic detoxification of doxorubicin or urethane and/or a DNA repair inductor by recombination. There is a dose-dependent relationship.

These authors continued their studies and analyzed cubebin ability to interact with the enzyme system that catalyzes the urethane metabolic detoxification (carcinogen). This cubebin capacity was proved, by inhibiting the mitochondrial complex I activity, acting as a free radical scavenger. Furthermore, cubebin can modulate the urethane metabolic activation by inhibiting metabolites binding to the DNA (Rezende et al., 2013).

Cubebin can significantly inhibit CYP3A4 (Usia et al., $2005,2006)$ and the mitochondrial complex I activity of $\mathrm{NADPH}$ oxidase (Saraiva et al., 2009). According to Sinigaglia et al. (2006), co-treatments with oxidants and cubebin reduce the mutation rate, and may be classified as non-mutagenic effect. The cubebin non-mutagenic capacity is not very clear; it may be attributed to the antioxidant capacity and metabolic activity suppression.

In an in vitro study held in two different cell lines of human prostate cancer (LNCaP-FGC and PC-3) the anticancer potential of an ethanol extract of $P$. cubeba was evaluated, named, in that study, P9605. HPLC analysis revealed that the P9605 had $16.53 \%$ of cubebin. The results indicated that the P9605 inhibited proliferation of human $\mathrm{LNCaP}$ cells prostate cancer by reducing DNA synthesis and inducing apoptosis. The anti-growth effect was less pronounced in the PC-3 line. The P9605 markedly inhibited the 5a-reductase II activity, which is responsible for converting testosterone to its active form and suppressed PSA secretion in LNCaP cells, thus acting by several mechanisms (Yam et al., 2008).

Hinokinin differs from cubebin because of the presence of a carbonyl group at C-9. Hinokinin has been extensively studied and has shown great therapeutic potential, even in antitumor activity. Barbosa et al. (2014) tested the antigenotoxic and anticarcinogenic potential of hinokinin in preneoplastic lesions in rat colon. According to the authors hinokinin was able to reduce DNA damage induced by 1,2- dimethylhydrazine (DMH) and additionally inhibited the formation of pre-neoplastic lesions.

The antitumor activity of cubebin, isolated from dry seeds of $P$. cubeba and its semisynthetic derivatives (17) were tested in vitro in six different human tumor cell lines: A549 (human lung carcinoma), KB (human nasopharyngeal carcinoma), K562 (human chronic myeloid leukemia), SiHa (human cervical carcinoma), 
HT29 and HCT116 (human colon carcinoma). According to the results, which were expressed as IC50 (concentration able to inhibit cell growth by $50 \%$ ). Hinokinin and compounds containing group's amide and lactone ring were those who had higher activity on the test cells (Rajalekshmi et al., 2016).

\section{Activity in erectile dysfunction}

Erectile dysfunction (ED) is defined as the persistent inability to obtain and/or maintain an adequate penile rigidity which allows a satisfactory sexual intercourse, according to the National Institutes of Health $(\mathrm{NIH})$ on Impotence (Impotence, 1992).

Many plants metabolites produce vessel relaxation, mediated by nitric oxide (NO). Flavonoids, tannins, lignans can directly activate production of NO endothelial synthase or can enhance mediated relaxation by $\mathrm{NO}$ and by superoxide anions (Achike and Kwan, 2003).

Carvalho et al. (2013) investigated the vasorelaxant effect produced by cubebin from dry seeds of $P$. cubeba in aortic rings isolated of pre-contracted rats with phenylephrine to evaluate the possible mechanism involved. It has been suggested that cubebin has a vasorelaxant effect dependent on the NO/cGMP pathway. In addition to $\mathrm{NO}$, release of endothelial prostacyclin also contributes to the smooth muscle relaxation via cGMP (Parkington et al., 2004). However, in this case it was concluded that pretreatment with indomethacin failed to modify the relaxation induced by cubebin, suggesting that prostanoids do not contribute to the relaxing effect.

Researchers from the University of Franca (São Paulo, Brazil), have deposited a patent with the number of publication (WO 2011/075801 A1) regarding the use of dibenzyl butyrolactone lignan and its derivatives, as well as other lignans and neolignans, and in particular with cubebin as a vasodilator agent in erectile dysfunction therapy. They conducted in vivo tests using Swiss mice. The mice were divided into groups receiving different cubebin doses, negative control groups and groups receiving treatment with sildenafil citrate (positive control). The research group observed that the use of cubebin showed positive effects similar to the drugs currently used for treating male impotence, particularly Viagra, with no tachycardia and the inherent agitation. The suggested mechanism of action was PDE5 blocking (diestarase phosphorus 5).

\section{Trypanocidal activity}

Chagas disease is caused by the flagellate protozoan Trypanosoma cruzi, which is transmitted to the human host, mainly by the hematophagous vector known as "the barber bug" (Triatoma infestans, Panstron-gylus megistus, among others). There are also other possible types of transmission such as blood transfusions, motherto-child transmission and more rarely by contaminated fresh food (Moncayo and Ortiz Yanine, 2006). This disease affects about 10 million people in Latin America (Rassi et al., 2010).

Drugs available for this disease treatment include benznidazole (Rochagan, Roche) and nifurtimox (Lampit, Bayer), although these drugs cause several side effects. Moreover, there are already $T$. cruzi resistant to treatment (Coura, 2009).

The $T$. cruzi biological cycle is highly complex, involving three different ways: Epimastigote (proliferative form), trypomastigote (infective and bloodstream form) and amastigote (intracellular replication form). This may hinder drug discovery.

Bastos et al. (1999) evaluated some biologically active dibenzyl butyrolactone lignans, isolated from Zanthoxyllum naranjillo leaves, which showed cubebin and methylpluviatolide trypanocidal action.

Souza et al. (2005) evaluated the cubebin derivatives activity (isolated from the $P$. cubeba dry seeds) against amastigotes forms of Trypanosoma cruzi in a cell culture assay. Biological activity was assessed using a colorimetric method and the statistical analyzes were performed by the ANOVA test. According to the article, the most active compound was hinokinin with an $\mathrm{IC}_{50}$ value of $0.7 \mu \mathrm{M}$. Benzyl cubebin $\left(\mathrm{IC}_{50} 5.7 \mu \mathrm{M}\right)$ and $\mathrm{O}-\mathrm{N}$, $\mathrm{N}$-dimethylaminoethyl-cubebin $\left(\mathrm{IC}_{50} 4.7 \mu \mathrm{M}\right)$ also had significant activity. O-acetyl cubebin was inactive and 6,6dinitro hinokinin presented $\mathrm{IC}_{50} 95.3 \mu \mathrm{M}$. The researchers concluded that the nitro group was harmful to this activity.

In vitro and in vivo studies on cubebin and derivatives activity against Trypanosoma cruzi were carried out by Saraiva et al. (2007). Cubebin was isolated from $P$. cubeba dry seeds and its derivatives were obtained by HPLC after partial and purified synthesis.

Cubebin, benzyl cubebin and dinitro hinokinin showed low anti-epimastigote activity in in vitro assay. Methylcubebin, hinokinin and dimethyl-morelensine showed high activity in that assay. Hinokinin had $\mathrm{IC}_{50}$ of $0.67 \mu \mathrm{M}$ and was selected to in vivo study. The researchers observed a $70.8 \%$ reduction of parasitaemia (amastigotes), while benznidazole reduced parasitaemia in $29.0 \%$, making hinokinin a potential drug for Chagas disease, according to the authors.

In an in vivo study, Esperandim et al. (2010) evaluated the trypanocidal activity of cubebin and hinokinin during the chronic Chagas disease phase. Hinokinin was obtained by partial synthesis of cubebin isolated from $P$. cubeba dry seeds.

Albino BALB/c mice were used in that study, they divided into groups according to the drug administration type (oral and intraperitoneal) and dosage (20 and 50 $\mathrm{mg} / \mathrm{Kg}$ ). A negative group was also separated (inoculated with trypomastigotes), treated with the solvent used to prepare the solutions, a positive group treated with benznidazole and an uninfected group. In all cases, the 
treatment was initiated 90 days after infection. Parasitism reduction was assessed by the $\beta$-galactosidase quantification. Treatment with lignans led to higher reduction of parasitism in all organs evaluated in comparison with benznidazole. Oral treatment was more effective. The data suggested that cubebin and hinokinin can be considered as potential compounds for the development of new drugs against Chagas disease.

Hinokinin and 6,6-dinitro hinokinin were evaluated for their interference with the messenger RNA processing in trypanosomatids. The study performed by Silva et al. (2011) used T. cruzi epimastigotes strains $Y$ and BOL (Bolivia). The substances seemed to intervene at some RNA transcription stage, promoting changes in their synthesis. Hinokinin and 6,6-dinitro hinokinin were not able to interfere with RNA processing by trans-splicing in $T$. cruzi, as observed by the RNase protection reaction.

Continuing the 2010 studies, researchers conducted an in vivo study in order to verify cubebin and hinokinin activity against $T$. cruzi. Cubebin was obtained in the same way as the previous study. In a study with BALB/C mice, they were inoculated with $2 \times 10^{4}$ trypomastigotes forms $48 \mathrm{~h}$ before treatment. The mice were divided into 6 groups: Negative control (5\% i.p. injection with 5\% DMSO, 2.5\% Tween, 5\% ethanol); positive control (benznidazole, 20 and $50 \mathrm{mg} / \mathrm{Kg}$ p.o.); cubebin (20 and $50 \mathrm{mg} / \mathrm{kg}$ p.o.); hinokinin (20 and $50 \mathrm{mg} / \mathrm{Kg}$ p.o.); during the acute phase of the $T$. cruzi infection. The animals with acute parasitaemia were investigated by morphometric tissue analysis. There was a significant parasitaemia reduction in animals treated with cubebin and hinokinin compared to the negative control (Esperadim et al., 2013).

\section{Anti-Leishmania activity}

Leishmaniasis is a group of tropical diseases caused by trypanosomatidae protozoa, with more than 30 species, of which 11 have medical and veterinary significance (Bates, 2007). Leishmaniasis has a major impact on populations worldwide, particularly in Asia, Africa and Latin America (Chan-Bacab, Pena-Rodriguez, 2001). More than 350 million people live in areas at risk of infection with active parasite (Murray et al., 2005).

Leishmania spp. infection can lead to different clinical manifestations depending on the species of Leishmania and host immune response. There are three main types: Cutaneous, mucocutaneous and visceral. Visceral leishmaniasis is caused by L. donovani, the most severe form of leishmaniasis and when left untreated can be fatal (Ready, 2014). Cutaneous and mucocutaneous leishmaniasis are more common and usually appear as an ulcer that can take months or years to heal and may become chronic (Salman et al., 1999).

Leishmania can be considered an opportunistic pathogen in HIV-positive patients, immunocompromised, and stimulate virus replication in these patients (Carvalho and Ferreira, 2001).

Drugs of choice for leishmaniasis treatment are pentavalent antimonials, which have high renal and cardiac toxicity. Therefore, there is the need for other drugs that are safe and effective.

Bodiwala et al. (2007) investigated amides and lignans of $P$. cubeba and Piper retrofractum. Two lignans were isolated: Cubebin and hinokinin of hexane extract of $P$. cubeba, and sesamin lignan and two amides, pellitorine and piplartine, of methanol and hexane extracts of $P$. retrofractum. In vitro cytotoxicity assays were performed to assess activity against promastigotes, using the MTT colorimetric method [3- (4.5-dimethylthiazol-2-yl) -2.5diphenylterazolium bromide] and in vivo assays against amastigotes using infected hamsters. In both tests the species $L$. donovani was used.

According to the results of the research group, cubebin and piplartine showed high in vitro activity at $100 \mu \mathrm{M}$ concentrations and were tested in vivo in a visceral leishmaniasis model in hamsters. Piplartine showed in vivo activity at $30 \mathrm{mg} / \mathrm{Kg}$.

\section{Antibacterial activity against oral pathogens}

Tooth cavity is a multifactorial, chronic infectious disease, which puts people at risk not only in childhood and adolescence, but throughout life. It is the most common cause of pain in the oral cavity and tooth loss (Edelstein, 2006; Featherstone, 2004). Tooth cavity develops an imbalance in the oral microflora and may be triggered by the presence of bacteria, genetic and immunological factors and behavioral aspects which interact, allowing the initiation and development of tooth cavities (Selwitz et al., 2007; Aas et al., 2008). Studies point to Streptococcus mutans as the primary pathogen in the etiology of tooth cavity (Hoiby et al., 2011; Tanzer et al., 2001).

Silva et al. (2007) investigated ethanol extract activity of $P$. cubeba, cubebin and semisynthetic derivatives against oral pathogens. Pathogens chosen to participate in the survey were: Streptococcus salivaris, Streptococcus mitis, Enterococcus faecalis, Streptococcus mutans, Streptococcus sobrinus, Streptococcus sanguinis and Candida albicans. Microdilution was the method used in the evaluation. MIC (minimal inhibitory concentration) was defined as the lowest concentration that did not allow any growth on blood agar, and lack of growth of viable cells indicated a bactericidal effect. The extract of $P$. cubeba, cubebin and its derivatives showed activity against all the microorganisms tested. According to the research group analysis, introducing polar groups in aromatic ring was beneficial for antimicrobial activity.

\section{PERSPECTIVES AND CONCLUSION}

The Piper genus has been very studied by scientists 
worldwide. It a genus that can be found in all continents, with several species. In this concept, the main compounds isolated from two species have shown potential to become new molecules, in its natural or semisynthetic forms (O-benzyl cubebin, 6,6'-dinitrohinokinin, amide derived from hinokinin), for the therapeutical proposes. Researchers have been studying cubebin and its derivatives by semisynthesis and have found great therapeutic perspectives. Substitutions on the cubebin aromatic ring, according to the desired derivative, specifically influence each biological activity studied. Cubebin has proven in vivo efficacy in most of the activities described in the article. Therefore, more detailed studies is necessary about its activity in living organisms. Hinokinin can be isolated from $P$. cubeba or semi-synthesized by oxidation of cubebin. This substance has demonstrated high analgesic activity and antiinflammatory, antimutagenic, chemopreventive, anticancer activities, in the treatment of Chagas disease and antibacterial activity against oral pathogens. The hinokinin certainly deserves attention and has a great therapeutic potential. Considering the patents on the use of cubebin and conduction of non and clinical trials, undoubtedly, in a few years it is possible to have a new drug arising from natural products studies to be used as new medicinal agent.

\section{Conflict of Interests}

The authors have not declared any conflict of interests.

\section{ACKNOWLEDGEMENT}

The authors thank Espaço da Escrita - Coordenadoria Geral da Universidade - UNICAMP - for the language services provided.

\section{REFERENCES}

Aboul-Eneim HY, Kladna A, Kruk I (2011). Radical scavenging ability of some compounds isolated from Piper cubeba towards free radicals. Luminescence 26:202-207.

Aas JA, Griffen AL, Dardis SR, Lee AM, Olsen I, Dewhirst FE (2008). Bacteria of dental caries in primary and permanent teeth in children and young adults. J. Clin. Microbiol. 46:1407-1417.

Achike FI, Kwan CY (2003). Nitric oxide, human diseases and the herbal products that affect the nitric oxide signalling pathway. Clin. Exp. Pharmacol. Physiol. 30:605-615.

Barbosa FJM (2004). Lignanas, Neolignanas E Seus Análogos. In: Simões CMO, Schenkel EP, Gosmann G, Mello JCP, Mentz LA, Petrovick PR (Org.). Farmacognosia: da planta ao medicamento, $5^{\text {a }}$ ed. Editora da UFRGS/Editora da UFSC, Porto Alegre/Florianópolis, Brasil pp. 557-575.

Barbosa LC, Furtado RA, Bertanha HCC, Tomazella IM, Costa ES, Bastos JK, Silva MLA, Tavares DC (2014). Chemopreventive Effects of (-)-Hinokinin against 1,2- Dimethylhydrazine-Induced Genotoxicity and Preneoplastic Lesions in Rat Colon. J. Nat. Prod. 77:2312-2315.

Bastos JK, Albuquerque S, Silva MLA (1999). Evaluation of the trypanocidal activity of lignans isolated from the leaves of
Zanthoxylum naranjillo. Planta Medica 65:541-544.

Bastos JK, Carvalho JC, De Souza GH, Pedrazzi AH, Sarti SJ (2001). Antiinflammatory activity of cubebin, a lignan from the leaves of Zanthoxyllum naranjillo Griseb. J. Ethnopharmacol. 75:279-282.

Bates PA (2007). Transmission of Leishmania metacyclic promastigotes by phle- botominesa nd flies. Int. J. Parasitol. 37(10):1097-106.

Blumenthal EEA, Da Silva MS, Yoshida M (1997). Lignoids, flavonoids and polyketides of Virola surinamensis. Phytochemistry 46(4):745749.

Bodiwala HS, Singh G, Singh R, Dey CS, Sharma SS, Bhutani KK, Singh IP (2007). Antileishmanial amides and lignans from Piper cubeba and Piper retrofractum. J. Natural Med. 61:418-421.

Carvalho PB, Ferreira EI (2001). Leishmaniasis phytotherapy. Nature's leadership against an ancient disease. Fitoterapia 72:599-618.

Carvalho MTM, Rezende KCS, Evora PRB, Bastos JK, Cunha WR, Silva MLA, Celotto AC (2013). The Lignan (-)-Cubebin Inhibits Vascular Contraction and Induces Relaxation Via Nitric Oxide Activation in Isolated Rat Aorta. Phytother. Res. Res. 27:1784-1789

Chan-Bacab MJ, Pena-Rodrigues LM (2001). Plant natural products with leishmanicidal activity. Nat. Prod. Rep. 18:674-688

Coimbra H, Dos S, Royo V, De A, De Souza VA, Pereira AC, De Souza GHB, Da Silva R, Donate PM, Silva MLA, Cunha WR, Carvalho JCT, Bastos JK (2004). Analgesic and anti-inflammatory activities of (-)-o benzyl cubebin, a (-)-cubebin derivative ,obtainned by partial syntesis. Boll. Chim. Farmac. - Anno 143 - n. 2 Marzo 2004.

Coura JC (2009). Present situation and new strategies for Chaga's disease chemotherapy - a proposal. Mem. Inst. Oswaldo Cruz. 104:549-554.

De Pascoli IC, Nascimento IR, Lopes LM (2006). Configurational analysis of cubebins and bicubebin from Aristolochia lagesiana and Aristolochia pubescens. Phytochemistry 67(7):735-742.

De Rezende AAA, Silva MLA, Tavares DC, Cunha WR, Rezende KCS, Bastos JK, Lehmann M, De Andrade HHR, Guterres ZR, Silva LP, Spano MA (2011). The effect of the dibenzylbutyrolactolic lignan (-)cubebin on doxorubicin mutagenicity and recombinogenicity in wing somatic cells of Drosophila melanogaster. Food Chem. Toxicol. 49:1235-1241.

De Rezende AAA, Munari CC, De Oliveira PF, Ferreira NH, Tavares DC, Silva MLA, Rezende KCS, Spano MA (2013). A comparative study of the modulatory effects of (-)-cubebin on the mutagenicity/recombinogenicity induced by different chemical agents. Food Chem.Toxicol. 55:645-652.

De Souza VA, Silva R, Pereira AC, Royo VA, Saraiva J, Montanheiro M, Souza GHB, Filho AAS, Grando MD, Donate PM, Bastos JK, Albuquerque S,Silva MLA (2005). Trypanocidal activity of (_)-cubebin derivatives against free amastigote forms of Trypanosoma cruzi. Bioorganic Medicinal Chem. Letters 15:303-307.

Edelstein B (2006). The dental caries pandemic and disparities problem. BMC Oral. Health. 15:(Suppl 1)S2.

Esperandim VR, Ferreira DS, Saraiva J, Silva MLA, Costa EV, Pereira AC, Bastos JK, Albuquerque S (2010). Reduction of parasitism tissue by treatment of mice chronically infected with Trypanosoma cruzi with lignano lactones. Parasitol. Res. 107:525-530.

Esperadim VR, Ferreira DS, Rezende KCS, Cunha WR, Saraiva J, Bastos JK, Silva MLA, Albuquerque S (2013). Evaluation of the in vivo therapeutic properties of cubebin and hinokinin against Trypanosoma cruzi. Experimental Parasitol. 133:442-446.

Featherstone JDB (2004). The continuum of dental caries-evidence for a dynamic disease process. J. Dent. Res. 83:39-42.

Hardman JG, Molinoff PB, Gilman AG (1996). Goodman e Gilman: As bases farmacológicas da terapêutica. $9^{a}$ ed. Rio de Janeiro: McGrawHill. pp. 453-454.

Hoiby JS, Ciofu NO, Johansen HK (2011). The clinical impact of bacterial biofilms. Int. J. Oral. Sci. 3:55-65.

Impotence (1992). NIH Consens Statement. 10:1.

Junqueira APF, Perazzo FF, Souza GHB, Maistro EL (2007). Clastogenicity of Piper cubeba (Piperaceae) seed extract in an in vivo mammalian cell system. Genetics Molecular Biol. 30:656-663.

Mainenti P, Rosa LEB (2008). Carcinogênese química experimental em glândulas salivares - revisão da literatura. Revista Brasileira de Cancerologia. 54(2):167-174.

Moncayo A, Ortiz Yanine Ml (2006). An update on Chaga's disease 
human American trypanosomiasis. Ann. Trop. Med. Parasitol. 100:663-677.

Murray HW, Berman JD, Davies CR, Saravia NG (2005). Advances in leishmaniasis. Lancet 366(9496):1561-77.

Parkington HC Coleman HA, Tare M (2004). Prostacyclin and endothelium-dependent hyperpolarization. Pharmacol. Res. 49:509514.

Pessuto MB, Da Costa IC, De Souza AB, Nicoli FM, De Melo JCP, Petereit F, Luftmann H (2009). Atividade antioxidante de extratos e taninos condensados das folhas de Maytenus ilicifolia Mart. es Reiss. Química Nova 32(2):412-416.

Rao CBS (1978). Chemistry of lignans, University Press, Andhra Pradesh, India, p. 213.

Rajalekshmi DS, Kabeer FA, Madhusoodhanan AR, Bahulayan AK, Prathapan R, Prakasan N, Varughese S, Nair MS (2016). Anticancer activity studies of cubebin isolated from Piper cubeba and its synthetic derivatives. Bioorganic Med. Chem. Lett. 26:1767-1771.

Rassi Jr A, Rassi A, Marin-Neto JA (2010). Chagas's disease. Lancet $375: 1388-1402$.

Ready PD (2014). Epidemiology of visceral leishmaniasis. Clin. Epidemiol. 6:147-54.

Reitz PR (1960). Flora ilustrada Catarinense, first Ed. Santa Catarina, Brazil, pp. 13-14.

Rodrigues ER (2002). Estudos pré-clínicos de possíveis efeitos adversos da cubebina. Ribeirão Preto. (Tese Doutorado - Faculdade de Ciências Farmacêuticas de Ribeirão Preto - USP).

Saleem M, Kim HJ, Alic MS, Lee YS (2007). An update on management of Chagas cardiomyopathy. Expert review of anti-infective therapy. Englant, 5:727-743.

Salman SM, Rubeiz NG, Kibbi AG (1999). Cutaneous leishmaniasis: clinical features and diagnosis. Clin. Dermatol. 17(3):291-296.

Saraiva J, Vega C, Rolon M, Da Silva R, Silva MLA, Donate PM, Bastos JK, Gomez-Barrio A, De Albuquerque S (2007). In vitro and in vivo activity of lignan lactones derivatives against Trypanosoma cruzi. Parasitol. Res. 100:791-795.

Saraiva J, Siqueira CM, Silva CHTP, Barreto VB, Tudella VG, Silva R, Andrade ESML, Dorta DJ, Bastos JK, Uyemura SA, De Albuquerque $S$, Curti C (2009). Cubebin and derivatives as inhibitors of mitochondrial complex I.Proposed interaction with subunit B8. J. Enzyme Inhib. Med. Chem. 24:599-606.

Selwitz RH, Ismail Al, Pitts NB (2007). Dental caries. The Lancet. 369:51-59.

Silva R, Souza GHB, Silva AA, Souza VA, Pereira AC, Royo VA, Silva MLA, Donate PM, Araújo ALSM, Carvalho JCT, Bastos JK (2005). Synthesis and biological activity evaluation of lignin lactones derived from (-)-cubebin. Bioorganic Med. Chem. Lett. 15:1033-1037.

Silva ML, Coimbra HS, Pereira AC, Almeida VA, Lima TC, Costa ES, Vinholis AH, Royo VA, Silva R, Filho AA, Cunha WR, Furtado NA, Martins CH, Carvalho TC, Bastos JK (2007). Evaluation of Piper cubeba extract, (-)-cubebinand its semi-synthetic derivatives against oral pathogens. Phytother. Res. 21:420-422.

Silva MLA, Cicarelli RMB, Pauletti PM, Luz PP, Rezende KCS, Januario $\mathrm{AH}$, Da Silva R, Pereira AC, Bastos JK, De Albuquerque $\mathrm{S}$, Magalhaes LG, Cunha WR (2011). Trypanosoma cruzi: evaluation of (-)-cubebin derivatives activity in the messenger RNAs processing. Parasitol. Res. 109:445-451.

Simões CMO, Schenkel EP, Gosmann G, Mello JCP De Mentz LA, Petrovick PR (1999). Farmacognosia: da Planta ao medicamento. Porto Alegre/Florianópolis: Ed. Universidade / UFRGS / Ed.da UFSC, p. 821.

Sinigaglia M, Lehmann M, Barumgardt $\mathrm{P}$, Amaral VS, Dihl RR, Reguly ML, De Andrade HHR (2006). Vanillin as a modulator agent in SMART test: inhibitionin the steps that precede $\mathrm{N}$-methyl- $\mathrm{N}$ nitrosourea-, $\quad \mathrm{N}$-ethyl-N-nitrosourea-,ethylmethanesulphonate- and bleomycin-genotoxicity. Mutat. Res. 607:225-230.

Souza GHB, Da Silva Filho AA, Pereira AC, De A, Royo VE, Silva MLA Da Silva MLA, Da Silva R, Donate PM, Carvalho JCT, Bastos JK (2004). Analgesic and anti-inflammatory activities evaluation of (-)-Oacetyl,(-)-O-methyl, (-)-O-dimethylethylamine cubebin and their preparation from (-)-cubebin. II Farmaco 59:55-61.

Souza VA, Silva R, Pereira AC, Royo VA, Saraiva J, Montanheiro M, Souza GHB, Filho AA, Da S, Grando MD, Donate MD, Bastos JK,
Albuquerme S, Silva MLA (2005). Trypanocidal activity of ()-cubebin derivatives against freeamastigote forms of Trypanosomacruzi. Bioorganic Med. Chem. Lett. 15:303-307.

Stutz A, Golenbock DT, Latz E (2009). Science in medicine: Inflammasomes: too big to miss. The Journal of Clinical Investigation 119(12):3502-3511.

Tanzer JM, Livingston J, Thompson AM (2001). The micro-biology of primary dental caries in humans. J. Dent. Educ. 65:128-137.

Usia T, Watabe T, Kadota S, Tezuka Y (2005). Metabolite-cytochrome P450 complex formation by methylenedioxyphenyl lignans of Piper cubeba:mechanism-based inhibition. Life Sci. 76:2381-2391.

Usia T, Iwata H, Hiratsuka A, Watabe T, Kadota S, Tezuka Y (2006). CYP3A4 and CYP2D6 inhibitory activities of Indonesian medicinal plants. Phytomedicine 13:67-73.

Vainio H, Magee P, Mcgregor D, Mcmichael AJ (1992). Mechanisms of carcinogenesis in risk identification. Lyon: International Agency for Research on Cancer. pp. 8-54.

Vasconcelos SML, Goulart MOF, Moura JBF, Manfredini V, Benfato MS, Kubota LT (2007). Espécies reativas de oxigênio e de nitrogênio, antioxidantes e marcadores de danos oxidativos em sangue humano: principais métodos analíticos para sua determinação. Química Nova 30(5):1323-1338.

Yam J, Kreuter M, Drewe J (2008). Piper cubeba targets multiple aspects of the androgen-signalling pathway. A potential phytotherapy against prostate cancer growth? Planta Medica 74:33-38. 